Tropical Journal of Pharmaceutical Research September 2020; 19 (9): 1843-1849

ISSN: $1596-5996$ (print); 1596-9827 (electronic) (C) Pharmacotherapy Group, Faculty of Pharmacy, University of Benin, Benin City, 300001 Nigeria.

\title{
MiR-379 inhibits proliferation and induces apoptosis in multiple myeloma by targeting Y-box binding protein 1
}

\author{
Yunyun Wang ${ }^{1}$, Dexiang $\mathrm{Ji}^{2}$, Guoan Chen ${ }^{2 *}$ \\ ${ }^{1}$ Academic Affairs Office, ${ }^{2}$ Department of Hematology, The First Affiliated Hospital of Nanchang University, Nanchang City, \\ Jiangxi Province 330006, China \\ *For correspondence: Email: chenguoan0791@163.com; Tel: +86-791-88692625
}

Sent for review: 8 July 2020

Revised accepted: 30 August 2020

\begin{abstract}
Purpose: To determine the effect of miR-379 in multiple myeloma. Methods: Quantitative reverse transcription-polymerase chain reaction (qRT-PCR) was used to evaluate the expression of miR-379 in multiple myeloma cells. The effect of miR-379 on multiple myeloma progression was investigated by cell counting, bromodeoxyuridine staining, flow cytometry and Western blot analysis. A potential target for miR-379 was determined using a luciferase reporter assay.

Results: MiR-379 expression was reduced in multiple myeloma cells, while over-expression of miR-379 increased both cell viability and proliferation of these cells $(p<0.05)$. Moreover, miR-379 blocked cell cycle multiple myeloma cells and promoted apoptosis by decreasing Bcl-2 expression, and increasing the expression of cleaved caspase-3 and Bax. MiR-379 bound to $Y$-box binding protein 1 (YBX1) and reduced YBX1 mRNA and protein expression in multiple myeloma cells $(p<0.05)$.

Conclusion: A YBX1-mediated tumor-suppressive role for miR-379 in multiple myeloma cells has been identified, suggesting a potential strategy for the treatment of multiple myeloma.
\end{abstract}

Keywords: MiR-379, Y-box binding protein 1, Multiple myeloma, Proliferation, Apoptosis

\begin{abstract}
This is an Open Access article that uses a fund-ing model which does not charge readers or their institutions for access and distributed under the terms of the Creative Commons Attribution License (http://creativecommons.org/licenses/by/4.0) and the Budapest Open Access Initiative (http://www.budapestopenaccessinitiative.org/read), which permit unrestricted use, distribution, and reproduction in any medium, provided the original work is properly credited.

Tropical Journal of Pharmaceutical Research is indexed by Science Citation Index (SciSearch), Scopus, International Pharmaceutical Abstract, Chemical Abstracts, Embase, Index Copernicus, EBSCO, African Index Medicus, JournalSeek, Journal Citation Reports/Science Edition, Directory of Open Access Journals (DOAJ), African Journal Online, Bioline International, Open-J-Gate and Pharmacy Abstracts
\end{abstract}

\section{INTRODUCTION}

Multiple myeloma is a common malignancy of the blood system, usually occurring in middle-aged and elderly individuals [1]. It is generally characterized by the malignant proliferation of plasma cells, and is accompanied by bone pain, fatigue, and other non-specific clinical symptoms [2]. In-depth studies investigating the pathogenesis of multiple myeloma are urgently needed to determine effective treatments for this disease.
Recently, a study revealed an important regulatory role of miRNAs in tumors [3], and in multiple myeloma. Furthermore, differentially expressed miRNAs have been shown to be relevant for both proliferation and the mass of tumors, which represent potential therapeutic targets [4]. MicroRNA-379 (miR-379) has been reported to inhibit migration and metastases in hepatocellular carcinoma [5], and the delivery of miR-379-overexpressing mesenchymal stem cells is reported to have a positive effect on the 
treatment of breast cancer [6]. However, a role for miR-379 in multiple myeloma has yet to be reported. More studies are needed to investigate a potential mechanism for the involvement of miR-379 in multiple myeloma to identify effective therapies for this disease.

Y-box binding protein 1 (YBX1) belongs to the super family of cold shock proteins that contain a highly conserved nucleic acid binding motif for binding to DNA and RNA [7]. YBX1 has been reported to be involved in multiple myeloma drug resistance [8], and to function as a binding target for miRNAs during tumor development [9]. However, the involvement of YBX1 in miR-379mediated multiple myeloma remains unknown.

The present study investigated the anticancer role of miR-379 in multiple myeloma, and then determined the potential miR-379-YBX1 network involved in tumor progression.

\section{EXPERIMENTAL}

\section{Cell culture}

Human multiple myeloma cells (RPMI-8226, NClH929, and U266) and normal bone marrowderived plasma cells (nPCs), were acquired from DSMZ (Braunschweig, Germany) and cultured in RPMI 1640 medium (Transgene, Beijing, China) containing $10 \%$ fetal bovine serum (Gibco, Carlsbad, CA, USA) at $37^{\circ} \mathrm{C}$ in an incubator.

\section{Cell transfections}

MiR-379 mimics, inhibitor and negative controls (NC mimic, NC inhibitor) were acquired from GenePharma (Shanghai, China). RPMI-8226 and $\mathrm{NCl}-\mathrm{H} 929$ cells were transfected with miR-379 mimics, inhibitor, NC mimic, and NC inhibitor using Lipofectamine 2000 (Invitrogen).

\section{Cell counting}

RPMI-8226 and $\mathrm{NCl}-\mathrm{H} 929$ cells were seeded and cultured for $24 \mathrm{~h}$. The cells were then incubated with $20 \mu \mathrm{l}$ of Cell Counting Kit-8 solution (Dojindo, Tokyo, Japan) for $2 \mathrm{~h}$, and the absorbance (450 $\mathrm{nm}$ ) was determined using an Epoch microplate Reader (BioTek, Winooski, VT, USA).

Table 1: Primer sequence

\section{Bromodeoxyuridine staining}

RPMI-8226 and $\mathrm{NCl}-\mathrm{H} 929$ cells were incubated with $100 \mathrm{nM}$ bromodeoxyuridine (Sigma-Aldrich, St. Louis, MO, USA) for $4 \mathrm{~h}$ before fixation using paraformaldehyde. After an incubation with $0.3 \%$ Triton X-100, $2 \mathrm{M}$ hydrochloric acid, and antipyonin, the cells were blocked and incubated with a primary antibody against bromodeoxyuridine (Abcam, Cambridge, UK). Cells were then incubated with a secondary antibody, and bromodeoxyuridine incorporation was analyzed using ImageXpress Micro XLS (Molecular Devices, Sunnyvale, CA, USA).

\section{Flow cytometry}

RPMI-8226 and NCl-H929 cells $\left(1 \times 10^{6}\right.$ cells) were fixed and incubated with $5 \mu \mathrm{l}$ of a $100 \mu \mathrm{g} / \mathrm{ml}$ propidium iodide solution containing $1 \mathrm{U} / \mathrm{ml}$ ribonuclease. Cell cycles were then determined using FACS flow cytometer (Attune, Life Technologies, Darmstadt, Germany). For apoptosis analysis, propidium iodide stained cells were incubated with an additional $5 \mu \mathrm{l}$ of fluorescein isothiocyanate-conjugated Annexin $\mathrm{V}$ before analysis using FACS flow cytometry.

\section{Dual luciferase reporter assay}

The YBX1 region with the miR-379 binding motif (or the region with a mutant binding motif) were introduced into the pGL-3-basic Firefly luciferase reporter vector (Promega, Madison, WI, USA). RPMI-8226 and NCl-H929 cells were cotransfected with either pGL-3-wt-YBX1 or pGL3-mut-YBX1 vectors, pRL-TK and miR-379 mimics, or NC mimic. Two days posttransfection, cell lysates were harvested, and luciferase activity was determined with the Luciferase Assay System (Promega).

\section{Quantitative reverse transcription (qRT-PCR)}

Total RNA, extracted from cells using the RNAsimple Total RNA Kit (TIANGEN, Beijing, China), and was reverse transcribed into cDNA, followed by qRT-PCR performed using a SYBR Green Master Mix (Solarbio, Beijing, China). The primer sequences used are listed below in Table 1.

\begin{tabular}{lll}
\hline Gene & Sense & Antisense \\
\hline miR-379 & 5'-GCTACATGATACAGTGCAAA-3' & 5'-AGTTTGCTTGATCCCTCTTCAG-3' \\
YBX1 & 5'-TAGACGCTATCCACGTCGTAG-3' & 5'-ATCCCTCGTTCTTTTCCCCAC-3' \\
GAPDH & 5'-GAGTCAACGGATTTGGTCGT-3' & 5'-GACAAGCTTCCCGTTCTCAG-3' \\
\hline
\end{tabular}




\section{Western blotting}

Cells were lysed using RIPA lysis buffer (Thermo Fisher, Waltham, MA, USA) and protein concentrations were determined using a Pierce ${ }^{\mathrm{TM}}$ BCA Protein Assay Kit (Thermo Fisher). Proteins $(30 \mu \mathrm{g})$ were separated using $8 \%$ SDS-PAGE, and electro-transferred onto polyvinylidene fluoride membranes (Bio-Rad, Hercules, CA, USA). After blocking, membranes were incubated with the following primary antibodies: YBX1 and cleaved caspase-3 (1:2000; Abcam), Bcl-2 and Bax (1:3000; Abcam), and $\beta$-actin (1:3000; Abcam). Membranes were then incubated with a horseradish peroxidaseconjugated secondary antibody (1:5000; Abcam), and chemiluminescence was determined using Pierce ECL Western Blotting Substrate (Pierce Biotechnology, Waltham, MA, USA).

\section{Statistical analysis}

All experiments were performed at least three times, and the data are reported as mean \pm standard deviation (SD). Student's $t$-test was applied for different group comparisons using Graphpad software (GraphPad Software, La Jolla, CA, USA). A value of $p<0.05$ was considered significant.

\section{RESULTS}

\section{Dysregulation of miR-379 in multiple myeloma}

For the determination of miR-379 differential expression in multiple myeloma cells, three human multiple myeloma cell types, RPMI-8226, $\mathrm{NCl}-\mathrm{H} 929$, and U266 were used for qRT-PCR analysis. The analysis showed a significant reduction in miR-379 expression in multiple myeloma cells compared to $\mathrm{nPCs} \quad(p<0.01)$ (Figure 1), suggesting that miR-379 may be involved in the regulation of multiple myeloma.

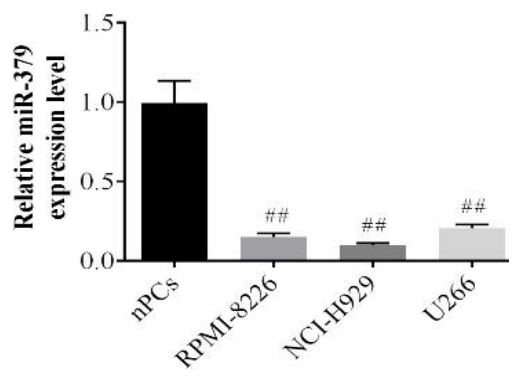

Figure 1: Dysregulation of miR-379 expression in multiple myeloma. The expression levels of miR-379 in three types of multiple myeloma cells (RPMI-8226, $\mathrm{NCl}-\mathrm{H} 929$, and U266) and in nPCs; \#\# $<0.01$
MiR-379 repressed multiple myeloma cell proliferation

To investigate the role of miR-379 in multiple myeloma, RPMI-8226 and $\mathrm{NCl}-\mathrm{H} 929$ cells were transfected with miR-379 mimics (Figure 2A), and significant decreases in cell viability were detected for these cells compared to the NC mimic group (Figure 2B). Moreover, a decrease in bromodeoxyuridine incorporation in RPMI8226 and $\mathrm{NCl}-\mathrm{H} 929$ cells transfected with miR379 mimics indicated that miR-379 repressed multiple myeloma cell proliferation (Figure 2C). Furthermore, miR-379 blocked the cell cycles of RPMI-8226 and NCl-H929 cells at the G0/G1 phase (Figure 3), demonstrating an antiproliferative effect of miR-379 on multiple myeloma.
A

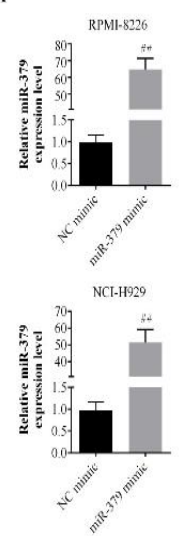

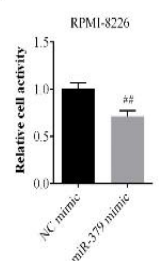

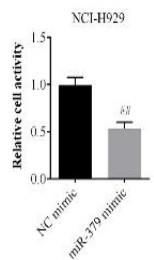

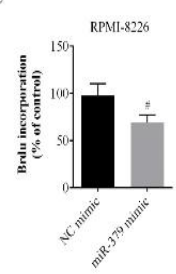

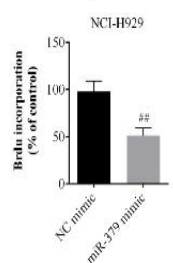

Figure 2: MiR-379 repressed cell proliferation in multiple myeloma. (A) Transfection efficiency of miR379 mimics in RPMI-8226 and $\mathrm{NCl}-\mathrm{H} 929$. (B) Effect of miR-379 on cell viability in RPMI-8226 and NCl-H929 cells. (C) Effect of miR-379 on cell proliferation in RPMI-8226 and NCl-H929 cells; \#p < 0.05, \#\#p $<0.01$
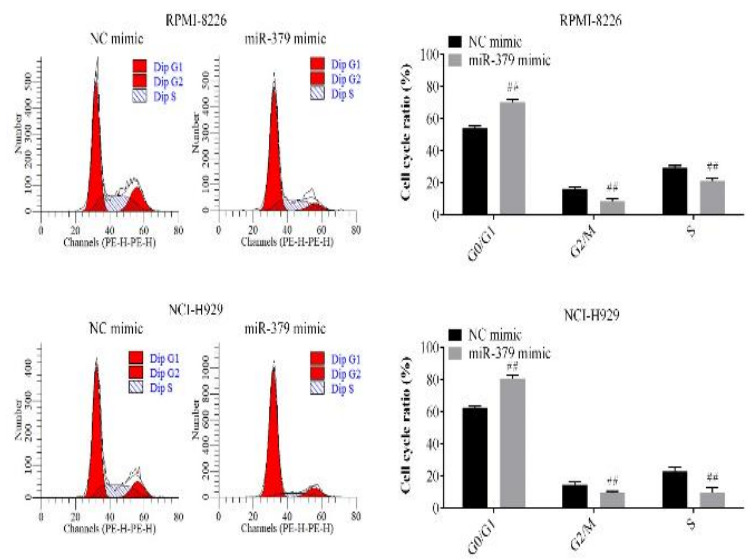

Figure 3: Effect of miR-379 on cell cycle in RPMI8226 and $\mathrm{NCl}-\mathrm{H} 929$ cell; \#\# $<0.01$ 


\section{MiR-379 promoted apoptosis in multiple myeloma cells}

The apoptosis ratio was evaluated in RPMI-8226 and $\mathrm{NCl}-\mathrm{H} 929$ cells using flow cytometry. The apoptosis ratios of RPMI-8226 and $\mathrm{NCl}-\mathrm{H} 929$ cells increased after transfection with miR-379 mimics (Figure 4), suggesting that miR-379 promoted multiple myeloma cell apoptosis. Western blot assessment of proteins involved in apoptosis revealed that miR-379 increased the levels of cleaved caspase- 3 and Bax, and decreased Bcl-2 levels in RPMI-8226 and NClH929 cells (Figure 5). This result confirms a proapoptotic role for miR-379 in multiple myeloma.
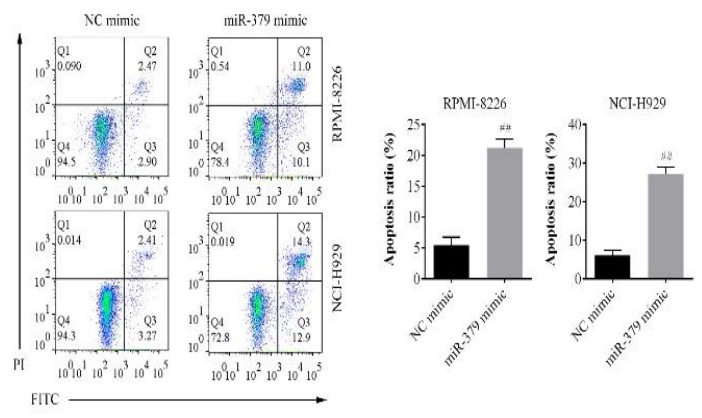

Figure 4: Effect of miR-379 on apoptosis in RPMI8226 and $\mathrm{NCl}-\mathrm{H} 929$ cells; \# $\quad$ < 0.01
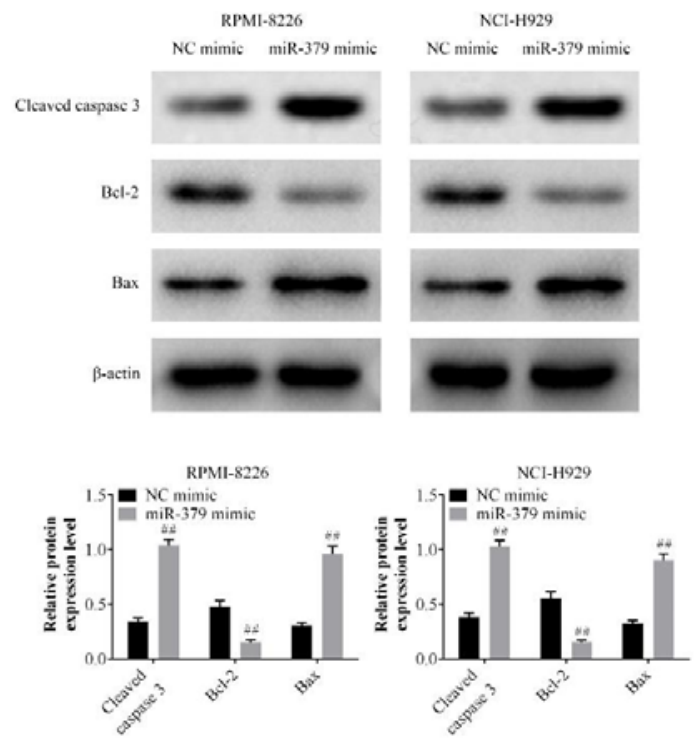

Figure 5: Effect of miR-379 on protein expression levels of cleaved caspase-3, Bcl-2, and Bax in RPMI8226 and $\mathrm{NCl}-\mathrm{H} 929$ cells; \#\# $<0.01$

\section{MiR-379 targeted YBX1}

A potential binding target for miR-379 was assessed as part of a possible molecular mechanism underlying miR-379-mediated multiple myeloma progression. YBX1 was identified as a potential target for miR-379 binding (Figure $6 \mathrm{~A}$ ), and the luciferase assay showed that miR-379 reduced pGL-3-wt-YBX1 luciferase activity in both RPMI-8226 and $\mathrm{NCl}-$ H929 cells (Figure 6 B). However, pGL-3-mutYBX1 luciferase activity was not significantly affected by the miR-379 mimic (Figure $6 \mathrm{~B}$ ). RPMI-8226 and $\mathrm{NCl}-\mathrm{H} 929$ cells were also transfected with an miR-379 inhibitor (Figure 6 C). YBX1 mRNA (Figure $7 \mathrm{~A}$ ) and protein (Figure 7B) expressions were reduced by the miR-379 mimics, and enhanced by the miR-379 inhibitor. Together, these results suggest that miR-379 may directly suppress the expression of YBX1.

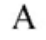

A

B
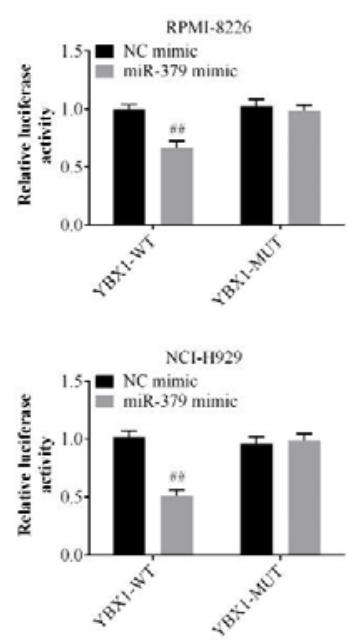

C
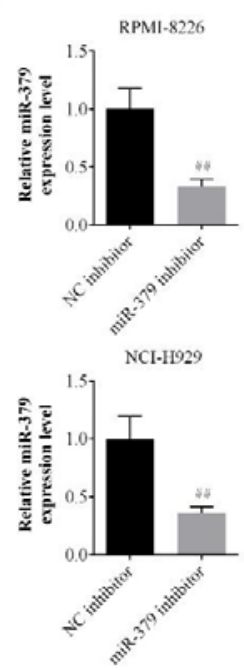

Figure 6: MiR-379 targeted YBX1. (A) The potential binding site, as well as the mutant binding site, between miR-379 and YBX1. (B) Effect of miR-379 on luciferase activities of pGL-3-wt-YBX1 or pGL-3-mutYBX1 in RPMI-8226 and NCl-H929 cells. (C) The transfection efficiency of miR-379 inhibitor in RPMI8226 and $\mathrm{NCl}-\mathrm{H} 929$ cells. \#\#p $<0.01$

\section{DISCUSSION}

The bone marrow microenvironment exerts a tumor-supportive influence and contributes to myeloma progression and the drug resistance observed in multiple myeloma [10]. MiRNAs derived from bone marrow adipocytes are reported to support myeloma-cell progression, and, therefore, represent promising therapeutic targets for multiple myeloma [10].

Trop J Pharm Res, September 2020; 19(9): 1846 

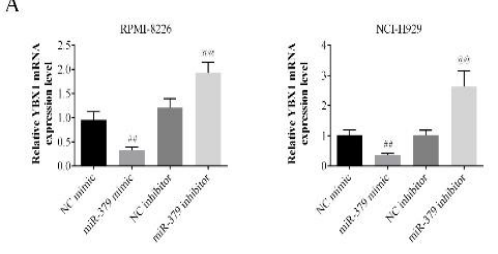

B
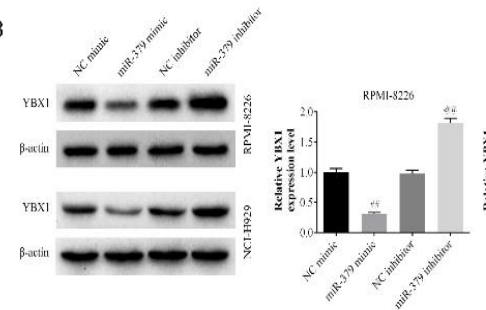

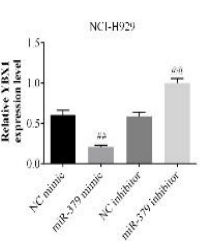

Figure 7: Effect of miR-379 on (A) mRNA and (B) protein expressions of YBX1 in RPMI-8226 and NClH929 cells. \#\#p $<0.01$

MiRNAs have also been shown to sustain multiple myeloma cell proliferation, help cells to evade cell-growth suppressors and increase celldeath resistance, foster genome instability, and activate metastasis in multiple myeloma; therefore, miRNAs can participate in tumor progression [11]. Considering the tumorsuppressive roles of miR-379 in a variety of cancers, the role of miR-379 in multiple myeloma was evaluated in the present study.

Aberrantly-expressed miRNAs are reported to be involved in the diagnosis, prognosis, and pathogenesis of multiple myeloma, suggesting multiple roles for miRNAs in this disease [12]. We found a significant down-regulation of miR379 in multiple myeloma cells when compared to normal bone marrow-derived plasma cells, this suggests that miR-379 may be a prognostic biomarker for multiple myeloma. Further analyses for any associations between miR-379 expression and overall survival or clinicopathological parameters in patients with multiple myeloma should be investigated to better understand the role of miR-379 in this disease.

Our data also revealed that miR-379 exerted an anti-proliferative influence and blocked cell cycling at the G0/G1 phase in multiple myeloma cells. Moreover, apoptosis in the multiple myeloma cells was also suppressed by miR-379 by decreasing the expression of $\mathrm{Bcl}-2$ and increasing the expression of cleaved caspase-3 and Bax. MiR-379 has also been reported to inhibit the epithelial-mesenchymal transition during gastric cancer progression [13]. The role of miR-379 in this process, as well as any target genes involved, specifically in multiple myeloma should be further investigated.
YBX1 may interact with the Y-box sequence (5'CTGATTGG-3') in promoter or enhancer regions of downstream genes to regulate the expression of proteins involved in cancer-cell cycling, proliferation, apoptosis, and in epithelialmesenchymal transitions [14]. Activation of YBX1 has been reported to occur through phosphorylation at serine 102 by AKT [15] or by ERK [16], before being translocated to the nucleus to perform its oncogenic role in a variety of tumor types. Depletion of YBX1 has been reported to repress tumor growth [17], suggesting its potential as a novel therapeutic target. Previous experiments have shown that the knockdown of YBX1 promoted apoptosis and reduced cell viability in multiple myeloma [8], and that MYC may drive transcription of YBX1 to facilitate the survival of multiple myeloma cell [18].

Here, we demonstrate for the first time that YBX1 is implicated in miR-379-mediated multiple myeloma progression. MiR-379 inhibited proliferation, and induced apoptosis, in multiple myeloma cells through the down-regulation of YBX1. However, rescue experiments using the over-expression of YBX1 should be conducted in the future to confirm the regulatory role of miR$379 /$ YBX1 in multiple myeloma. Moreover, posttranslational modifications of YBX1 (e.g., phosphorylation, acetylation, methylation, and ubiquitylation) may also modulate cancer progression [19]. In addition, pathways, such as PI3K/Akt/mTOR, Ras/Raf/MEK/ERK, and MAPK, have been shown to be involved in YBX1mediated cancer progression [14]. These potential YBX1 modifications and downstream pathways involved in miR-379-mediated multiple myeloma, warrant future investigation.

\section{CONCLUSION}

We have demonstrated in this study that MiR379 has both anti-proliferative and pro-apoptotic roles in multiple myeloma through direct regulation of YBX1. Therefore, the targeted delivery of miR-379 may be of therapeutic value to suppress multiple myeloma progression.

\section{DECLARATIONS}

\section{Acknowledgement}

This work was supported by International Collaboration Fund from National Science and Technology Committee of China (grant no. 2011DFA32820), National Natural Science Fund Project (grant no. 81460037) and by Fund of 
Jiangxi Provincial Department of Education (grant no. GJJ160240).

\section{Competing interests}

The authors state that there are no conflicts of interest to disclose.

\section{Contribution of authors}

We declare that this work was done by the authors named in this article and all liabilities pertaining to claims relating to the content of this article will be borne by the authors. Yunyun Wang designed the study, supervised the data collection, and analyzed the data. Guoan Chen interpreted the data and prepared the manuscript for publication. Dexiang Ji supervised the data collection, analyzed the data and reviewed the draft of the manuscript. All authors have read and approved the manuscript for publication.

\section{Open Access}

This is an Open Access article that uses a funding model which does not charge readers or their institutions for access and distributed under the terms of the Creative Commons Attribution License (http://creativecommons.org/licenses/by/ 4.0) and the Budapest Open Access Initiative (http://www.budapestopenaccessinitiative.org/rea d), which permit unrestricted use, distribution, and reproduction in any medium, provided the original work is properly credited.

\section{REFERENCES}

1. Zhu H, Si Y, Zhuang Y, Li M, Ji J, Ji O, Shen Q. PSAT1 prompted cell proliferation and inhibited cell apoptosis in multiple myeloma through regulating PI3K/AKT pathway. Trop J Pharm Res 2020; 19(4): 745-749.

2. Rieneke van de Ven SEV, Marjon Al, Henk Dekker, Henk M.W. Verheul, Janet L. Anderl, Elena T. Chan, Ben A.C. Dijkmans, Willem F. Lems, Rik J. Scheper, Gerrit Jansen, Tanja D. de Gruijl. Enhanced Dendritic Cell Development Through Long-Term Proteasome Inhibition. J Mol Clin Med 2018; 1(1): 37-46.

3. Peng $Y$, Croce $C M$. The role of MicroRNAs in human cancer. Signal Transduct Tar 2016; 1(1): 15004.

4. Seckinger A, Meißner T, Moreaux J, Benes V, Hillengass $J$, Castoldi $M$, Zimmermann $J$, Ho $A D$, Jauch $A$, Goldschmidt $H$ et al. miRNAs in multiple myeloma--a survival relevant complex regulator of gene expression. Oncotarget 2015; 6(36): 39165-39183.

5. Chen J-S, Li H-S, Huang J-Q, Dong S-H, Huang Z-J, Yi W, Zhan G-F, Feng J-T, Sun J-C, Huang $X-H$. MicroRNA-379-5p inhibits tumor invasion and metastasis by targeting FAK/AKT signaling in hepatocellular carcinoma. Cancer Lett 2016; 375(1): 7383.

6. O'Brien KP, Khan S, Gilligan KE, Zafar H, Lalor P, Glynn $C$, O'Flatharta $C$, Ingoldsby $H$, Dockery $P$, De Bhulbh A et al. Employing mesenchymal stem cells to support tumor-targeted delivery of extracellular vesicle (EV)encapsulated microRNA-379. Oncogene 2018; 37(16): 2137-2149.

7. Kuwano $M$, Oda $Y$, Izumi $H$, Yang $S-J$, Uchiumi $T$, Iwamoto $Y$, Toi M, Fujii $T$, Yamana $H$, Kinoshita $H$ et al. The role of nuclear $Y$-box binding protein 1 as a global marker in drug resistance. Mol Cancer Ther 2004; 3(11): 1485.

8. Chatterjee M, Rancso C, Stühmer T, Eckstein N, Andrulis $M$, Gerecke C, Lorentz H, Royer H-D, Bargou RC. The $Y$-box binding protein $Y B-1$ is associated with progressive disease and mediates survival and drug resistance in multiple myeloma. Blood 2008; 111(7): 3714-3722.

9. $X u$ S, Wang $T$, Song $W$, Jiang $T$, Zhang $F$, Yin $Y$, Jiang $S-W, W u K, Y u Z$, Wang $C$ et al. The inhibitory effects of AR/miR-190a/YB-1 negative feedback loop on prostate cancer and underlying mechanism. Sci Rep 2015; 5: 13528-13528.

10. Soley L, Falank C, Reagan MR. MicroRNA Transfer Between Bone Marrow Adipose and Multiple Myeloma Cells. Curr Osteoporos Rep 2017; 15(3): 162-170.

11. Caracciolo D, Montesano M, Altomare E, Scionti F, Di Martino MT, Tagliaferri $P$, Tassone $P$. The potential role of miRNAs in multiple myeloma therapy. Expert Rev Hematol 2018; 11(10): 793-803.

12. Chi J, Ballabio E, Chen XH, Kusec R, Taylor S, Hay D, Tramonti D, Saunders NJ, Littlewood T, Pezzella $F$ et al. MicroRNA expression in multiple myeloma is associated with genetic subtype, isotype and survival. Biol Direct 2011; 6(1): 23.

13. Xu M, Qin S, Cao F, Ding S, Li M. MicroRNA-379 inhibits metastasis and epithelial-mesenchymal transition via targeting FAK/AKT signaling in gastric cancer. Int $\mathrm{J}$ Oncol 2017; 51(3): 867-876.

14. Maurya PK, Mishra A, Yadav BS, Singh S, Kumar $P$, Chaudhary A, Srivastava S, Murugesan SN, Mani A. Role of $Y$ Box Protein-1 in cancer: As potential biomarker and novel therapeutic target. J Cancer 2017; 8(10): 1900-1907.

15. Basaki $Y$, Hosoi F, Oda $Y$, Fotovati A, Maruyama $Y$, Oie $S$, Ono $M$, Izumi $H$, Kohno $K$, Sakai $K$ et al. Aktdependent nuclear localization of $Y$-box-binding protein 1 in acquisition of malignant characteristics by human ovarian cancer cells. Oncogene 2007; 26(19): 27362746.

16. Imada $K$, Shiota $M$, Kuroiwa $K$, Sugimoto $M$, Abe $T$, Kohashi $K$, Yokomizo A, Eto $M$, Naito $S$, Oda $Y$. FOXO3a Expression Regulated by ERK Signaling is Inversely Correlated With Y-Box Binding Protein-1 Expression in Prostate Cancer. Prostate 2017; 77(2): 145-153.

Trop J Pharm Res, September 2020; 19(9): 1848 
17. Kim A, Shim S, Kim Y-h, Kim M-J, Park S, Myung JK. Inhibition of $Y$ Box Binding Protein 1 Suppresses Cell Growth and Motility in Colorectal Cancer. Mol Cancer Ther 2020; 19(2): 479.

18. Bommert KS, Effenberger M, Leich E, Küspert M, Murphy $D$, Langer C, Moll R, Janz S, Mottok A, Weissbach S et al. The feed-forward loop between YB-1 and MYC is essential for multiple myeloma cell survival. Leukemia 2013; 27(2): 441-450.

19. Prabhu L, Hartley A-V, Martin M, Warsame F, Sun E, Lu T. Role of post-translational modification of the $Y$ box binding protein 1 in human cancers. Genes Dis 2015; 2(3): $240-246$. 